\title{
Experimental Study on Ultra-lightweight Fire-resistive Engineered Cementitious Composite
}

\author{
Guo YANG ${ }^{1, a,{ }^{*},}$ Zhi-Yuan $\mathrm{LI}^{1, b}$ \\ ${ }^{1}$ College of Civil Engineering, Tongji University, Shanghai 200092, China \\ ayangguozhangshu@163.com, ${ }^{b}$ tjlizhiyuan@126.com \\ ${ }^{*}$ Corresponding author
}

Keywords: Ultra-lightweight, Fire-resistive, Engineered Cementitious Composite, Strain hardening, Poly-Vinyl Alcohol (PVA) Fibers, Density, Mechanical Properties.

\begin{abstract}
A special material, ULFR-ECC (Ultra-lightweight fire-resistive engineered cementitious composite), is introduced as a new kind of fire insulation. As a special member in the family of ECC (engineered cementitious composites), ULFR-ECC with a dry density of $566 \mathrm{~kg} / \mathrm{m}^{3}$ possesses the characteristics of strain hardening, ultra-ductility and also those in normal fire retardant coating, like lightweight and thermal insulation. Used as fire insulation on steel structure, ULFR-ECC may solve the existing issues of normal non-bulgy inorganic fire insulation, like debonding and dropping off at high stress condition or under earthquake impact. This paper presents the process of producing ULFR-ECC, including the mix proportions and mixing \& curing. Additionally, the physical and mechanical properties of ULFR-ECC with 3 different poly-vinyl alcohol fiber volume fractions were experimentally studied. The test results indicate all the tested ULFR-ECCs exhibit multi-cracks and strain hardening both under tension and compression. The strain corresponding to the peak tensile strength reached $2.17 \%, 2.73 \%$ and $2.81 \%$, and the strain to the $80 \%$ of peak compressive strength reached $1.95 \%, 1.83 \%$ and $2.24 \%$. Owing to the superior mechanical property, ULFR-ECC makes a new solution for the sustainability of fire insulation of steel structure.
\end{abstract}

\section{Introduction}

Having markedly strengthened the fire-resistant ability of steel structures, fire retardant coating serves as a main choice for steel fireproofing and drastically facilitates the application of steel construction $^{[1]}$. Admittedly, thick fire-retardant coating stands out for being economic and pragmatic due to its light weight, long fireproofing time, benign durability and none restraints for steel shape. However, it eclipses when applied to high stress conditions or earthquake circumstances owing to its deficiency in mechanical properties ${ }^{[2]}$. To specify, the inadequate compressive and tensile strength, and insufficient tenacity and ductility of the material is inclined to result in debonding, dropping off and other side effects for the whole construction ${ }^{[3]}$.

In this regard, the advancement for conventional fire-retardant coating is of supreme significance. Ultra-lightweight fire-resistive engineered cementitious composite (ULFR-ECC), a newly-developed material, is introduced as a new kind of fire insulation based on the design of microscopic mechanism $^{[4-5]}$. As a special member in the family of engineered cementitious composites (ECC), Ultra high toughness cementitious composites (UHTCC) was first invented by Professor $\mathrm{Li}^{[6]}$ in Michigan University with novel merits of strain hardening, ultra-ductility and regular advantages of light weight and high strength in usual thick coating with dry density reaching $857 \mathrm{~kg} / \mathrm{m}^{3}$, tensile strength achieving $1.2 \mathrm{Mpa}$ and peak strain attaining $2 \%$. Huang et al. lightened ECC by incorporating bubbles, hollow beads, light aggregate and glass pearls and found that the mix of glass pearls enables 
a mechanical feature of the whole material better than other counterparts ${ }^{[7]}$. Li ${ }^{[8]}$ pointed out that augment for the cohesive force in the interface of fiber and primary structure promotes the ductility of ECC.

This paper in detail introduces the manufacture process by material of PVA fiber, light aggregate, K20 glass microspheres and presents experimental study on ULFR-ECC with three samples of diverse fiber inserted amounts. By tensile test of dog bone samples and standard compressive test, the comparison on mechanical properties demonstrates that ULFR-ECC with dry density of $566 \mathrm{~kg} / \mathrm{m}^{3}$ not only achieves superbly high ultimate tensile strain and features of multi-cracks and strain hardening, but also exhibits preeminent heat insulation. It is conceivable that this coating will prevent the occurrence of excessive cracks and falling off to a large scale and protect steel from directly suffering fire exposure on account that the average width of cracks on coating will be no more than $60 \mu \mathrm{m}$. To sum up, ULFR-ECC reached in this paper ULFR-ECC manages a novel solution for the sustainability of fire insulation of steel structure due to its superior mechanical properties.

\section{Materials and Methods}

\section{Materials and Mix Proportions}

Three mixes of ULFR-ECC with different fiber volume fractions were first determined based on the strength and energy criteria of the ECC's design. Through trial testing, the mixes showed in Table 1 have benign mechanical properties and supremely low densities. The fiber was determined by the volume content while the others were measured by the mass. Type I Portland cement and Class F fly ash were utilized. K20, a kind of soda lime silicate glass microspheres, contributed to the improved density and thermal insulation. The material properties of the K20 and PVA fibers employed are listed in Tables 2 and 3, respectively. High-range water-reducer decreased water-cement ratio and reinforced strength without slump loss. The purpose of using thickening agent was to strengthen the bridging effect of PVA fibers through helping fibers spread in the cement matrix uniformly.

Tab.1 Mixture Proportion of ULFR-ECC

\begin{tabular}{ccccccc}
\hline $\begin{array}{c}\text { PVA } \\
\text { fiber } \\
\text { [volume] }\end{array}$ & $\begin{array}{c}\text { Cement } \\
{[\mathrm{g}]}\end{array}$ & $\begin{array}{c}\text { Fly ash } \\
{[\mathrm{g}]}\end{array}$ & $\begin{array}{c}\text { Water } \\
{[\mathrm{g}]}\end{array}$ & $\begin{array}{c}\text { K20 } \\
{[\mathrm{g}]}\end{array}$ & $\begin{array}{c}\text { Water-reducer } \\
{[\mathrm{g}]}\end{array}$ & $\begin{array}{c}\text { Thickening } \\
\text { agent }[\mathrm{g}]\end{array}$ \\
\hline $1 \%$ & 330 & 108 & 417 & 140 & 7 & 1 \\
$1.5 \%$ & 330 & 108 & 417 & 140 & 7 & 1 \\
$2 \%$ & 330 & 108 & 417 & 140 & 7 & 1 \\
\hline
\end{tabular}

Tab.2 Physical Properties of K20

\begin{tabular}{ccc}
\hline $\begin{array}{c}\text { Density } \\
{\left[\mathrm{kg} / \mathrm{m}^{3}\right]}\end{array}$ & $\begin{array}{c}\text { Average diameter } \\
{[\mu \mathrm{m}]}\end{array}$ & $\begin{array}{c}\text { Isostatic crush strength } \\
{[\mathrm{MPa}]}\end{array}$ \\
& & 3.5 \\
\hline 200 & $15-120$ & \\
\hline
\end{tabular}


Tab.3 Properties of PVA Fiber

\begin{tabular}{cccccc}
\hline $\begin{array}{c}\text { Average } \\
\text { diameter } \\
{[\mu \mathrm{m}]}\end{array}$ & $\begin{array}{c}\text { Length } \\
{[\mathrm{mm}]}\end{array}$ & $\begin{array}{c}\text { Nominal } \\
\text { strength } \\
{[\mathrm{MPa}]}\end{array}$ & $\begin{array}{c}\text { Young's } \\
\text { modulus } \\
{[\mathrm{GPa}]}\end{array}$ & $\begin{array}{c}\text { Elongation } \\
{[\%]}\end{array}$ & $\begin{array}{c}\text { Density } \\
{\left[\mathrm{kg} / \mathrm{m}^{3}\right]}\end{array}$ \\
$30 \sim 40$ & 12 & 1600 & 42 & 7 & 1300 \\
\hline
\end{tabular}

\section{Mixing and Curing}

In this study, the materials were added to the mixer in the order of K20, cement, fly ash, water reducer and water. It was necessary to make them infiltrating for about three minutes to avoid the fugitive dust because of the lightweight and small-sized K20. The cement matrix would be in good liquidity after mixing for about four minutes. It was time to add the PVA fibers slowly together with the thickening agent and then mixed for about three minutes until the fibers were well distributed. The mixture was cast into molds and covered with plastic sheets. Two days later, the specimens were demolded and put in standard curing room $\left(23 \pm 3^{\circ} \mathrm{C} ; 30 \pm 10 \%\right.$ relative humidity $)$ until the age of 28 $\operatorname{days}^{[9]}$.

\section{Mechanical and Density Testing}

The dog-bone-shaped specimens (Fig.1) were used to determine the tensile properties of ULFRECC after curing for 28 days, following the Japan Society of Civil Engineers (JSCE) ${ }^{[10]}$. Tests were performed on a tensile testing machine, under a displacement control at the rate of $0.5 \mathrm{~mm} / \mathrm{min}$. Specimens, subjected to quasi-static uniaxial tension, were attached by two external linear variable differential transformers (LVDTs) with the gage length of about $100 \mathrm{~mm}$ to attain statistics for computing tensile strain. The dog-bone-shaped specimens were also utilized to measure the density in accordance with the ASTM E605/E605M - 93 ${ }^{[11]}$.

The compression properties were acquired by a set of six $50 \mathrm{~mm}$ cube specimens tested at a loading rate of $1300 \mathrm{~N} / \mathrm{s}$ according to ASTM C109 ${ }^{[12]}$.
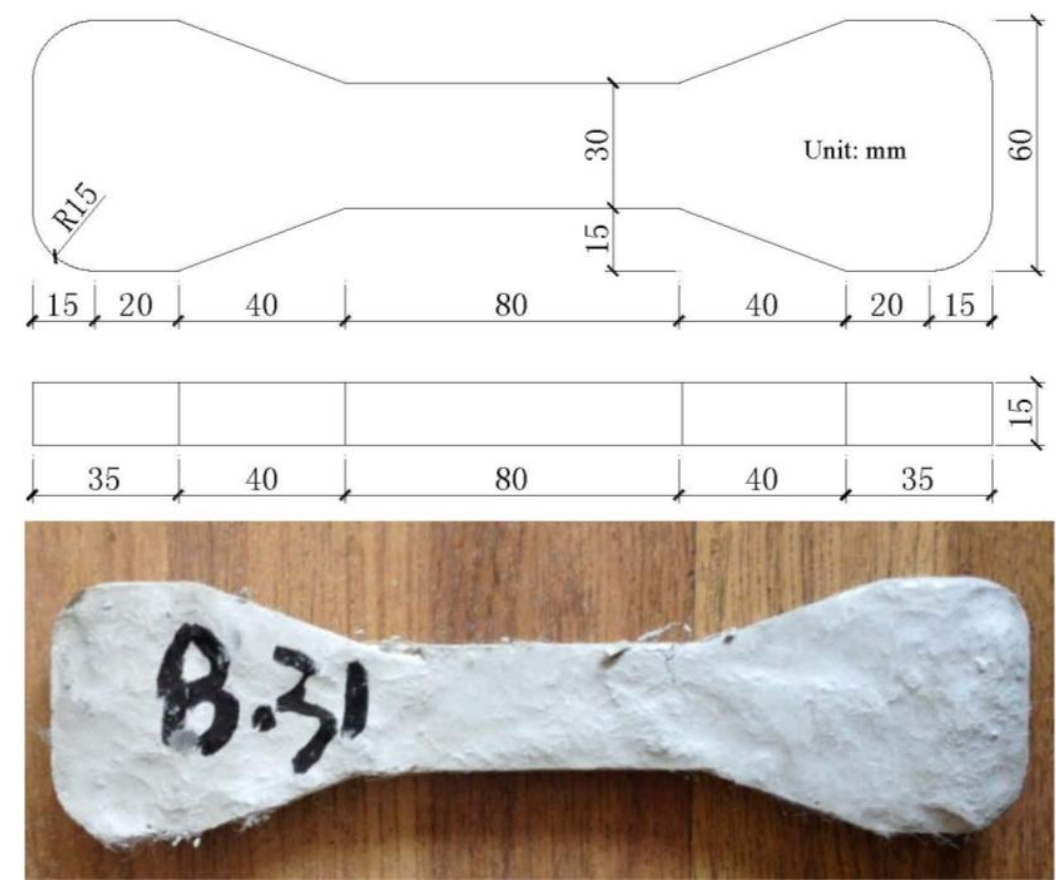

Fig. 1 The Size of Dog-bone Specimen 


\section{Results and Discussion}

\section{Density}

The dry density of ULFR-ECC measured with the displacement method is $566 \mathrm{~kg} / \mathrm{m}^{3}$. The significantly decreased density mainly contributed by the K20 makes it ideal to be a new material for fire insulation of steel structure.

\section{Tensile Properties}

During the tensile test, the three specimens exhibited common features. When the first crack appeared, all three specimens did experience local fracture. With tensile force multiplying, many small cracks occurred and developed on the surface. When the load continued to increase, a main crack which controlled the breakage of each sample appeared and there were many fibers being pulled out on the interface after each specimen was broken. There were many extremely tiny cracks which cannot be discovered by naked eyes after discharging and they were observed after the measure of plastering water on the surface ${ }^{[13]}$.

Fig.2a, 2b, and 2c illustrate the stain-stress relation of three fiber volumes under respectively six parallel experiments. From the figure, the curve became plane at the beginning and did not exhibit an obvious jump during ascending process. For specimens with $1.5 \%$ and $2 \%$ fiber aggregating, the curve experienced a slow rising, which connoted the appearance of strain hardening. As for the sample of $1 \%$ fiber mixing, the strain hardening occurred at the end of tensile test. Moreover, all three samples exhibited features of multi-cracks and cracks multiplied, turned slim and ultimate strain augmented with fiber a mount increasing.

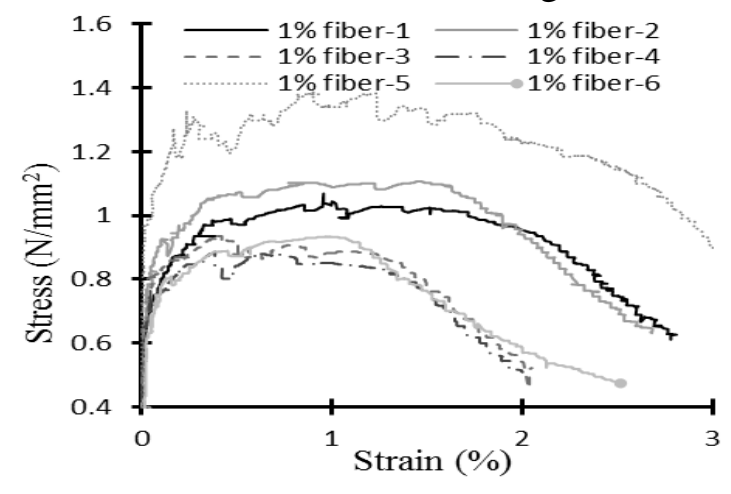

(2a)

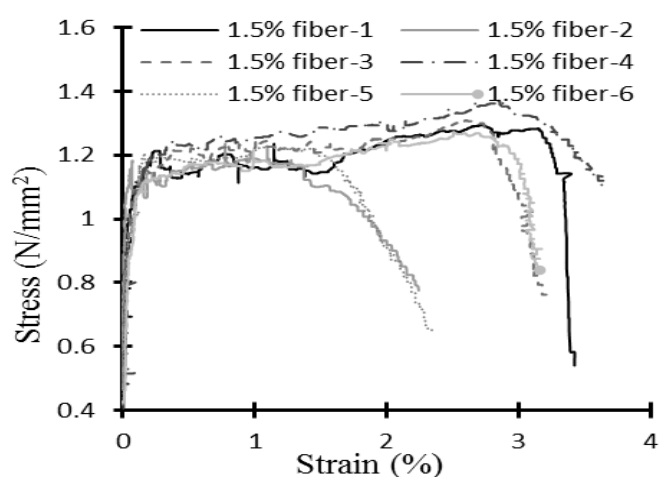

(2b)

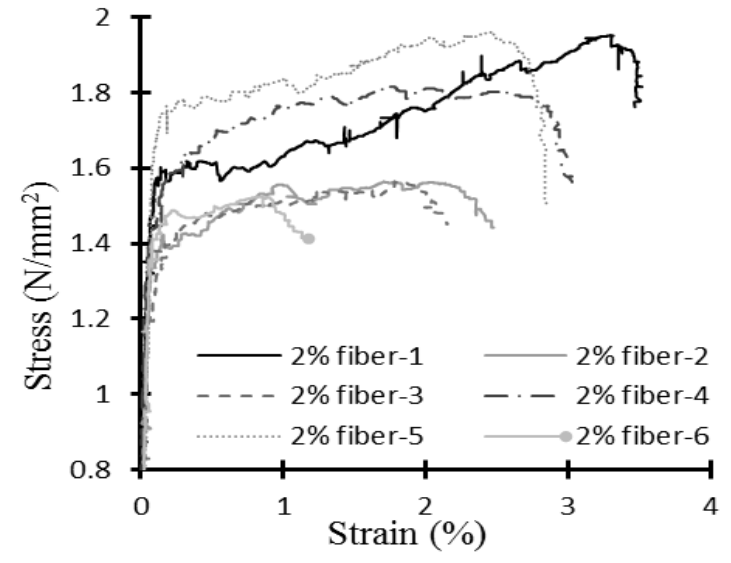

(2c)

Fig.2 The Effects of Fiber Volume on Tensile Stress-strain Curves (2a. 1\% Fiber Volume; 2b. 1.5\% Fiber Volume; 2c. 2\% Fiber Volume) 
Also, the cracking strength, strain, and tensile strength, strain, also elasticity modulus were calculated and exhibited in Table 4. Compared to the sample with $1 \%$ fiber, the specimen with $1.5 \%$ and $2 \%$ fiber respectively got their maximum tensile strength improved by $25.7 \%$ and $29.4 \%$ and elasticity modulus enhanced by $18.9 \%$ and $43.8 \%$. Therefore, adding fiber into ULFR-ECC in a proper scale strengthens the tensile mechanical capacity of the material, which corresponds to the result of Li's ${ }^{[14]}$.

Tab.4 Tensile Properties of ULFR-ECC

\begin{tabular}{c|c|c|c|c}
\hline $\begin{array}{c}\text { Fiber volume } \\
{[\%]}\end{array}$ & $\begin{array}{c}\text { Ultimate tensile } \\
\text { strength }[\mathrm{MPa}]\end{array}$ & $\begin{array}{c}\text { Tensile strain } \\
\text { capacity [\%] }\end{array}$ & $\begin{array}{c}\text { Cracking } \\
\text { strength [MPa] }\end{array}$ & $\begin{array}{c}\text { Elastic } \\
\text { modulus } \\
{[\mathrm{MPa}]}\end{array}$ \\
\hline 1.0 & $1.06 \pm 0.17$ & $2.17 \pm 0.44$ & $0.76 \pm 0.15$ & $965.9 \pm 161.0$ \\
\hline & $1.29 \pm 0.05$ & $2.73 \pm 0.46$ & $0.98 \pm 0.04$ & $1148.9 \pm 269.0$ \\
\hline 1.5 & & & & \\
\hline & $1.69 \pm 0.16$ & $2.81 \pm 0.42$ & $1.41 \pm 0.13$ & $1389.1 \pm 107.7$ \\
\hline
\end{tabular}

As a matter of fact, when the first crack appears, the fiber in the interface transfers the strength to unbroken area and those with more fiber amounts are able to support more loads, present stronger joint strength and better control the development of cracks $^{[15]}$. Furthermore, defects in material actually distributes at random. With the premise that defects allocates equally, ULFR-ECC with more fiber aggregating are more inclined to experience multi-cracking, thus presenting a better tensile capacity. As for the sample of $1 \%$ mixing fiber, it exhibited strain softening at the end of test due to its deficiency in connection by fibers.

\section{Compressive Properties}

After axial compression test, the strain-stress curve was illustrated in Fig.3. Compared with features of conventional cubic concrete, all the curve of the specimens presented a single partial peak. When samples achieved maximal strength, the curve did not descend, which illustrated that the samples remain relatively strong residual strength before breakage. By observing samples after compression, the specimens maintained integrated as a whole and did crack or fall off except for being axial compressed on the basis that the fiber in ULFR-ECC exerts remarkable joint effect by confining transverse deformation, averting abrupt brittle failure and signally enhances the ductility and shear strength of the material.

By comparison, all three samples with diversified fibers achieved a peak strain of nearly 0.02 , which is apparently better than that of conventional concrete because its summit strain merely attains 0.002 in most cases (see Fig.4a). Also, the compressive strength gets markedly promoted (see Fig.4b ) with sample of $1.5 \%$ and $2 \%$ fiber severally get compressive strength improved by $45.3 \%$ and $68.4 \%$ contrasted to that of specimen with $1 \%$ fiber (compressive strength equaling $2.97 \mathrm{Mpa}$ ). 


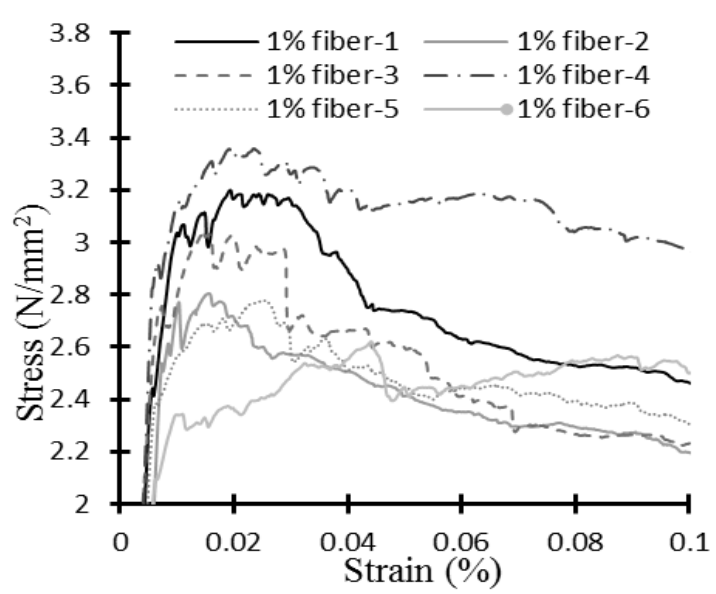

(3a)

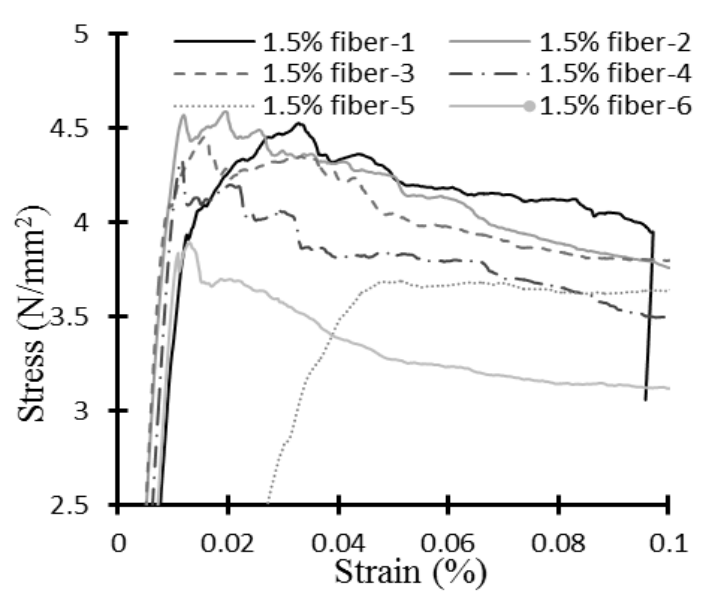

(3b)

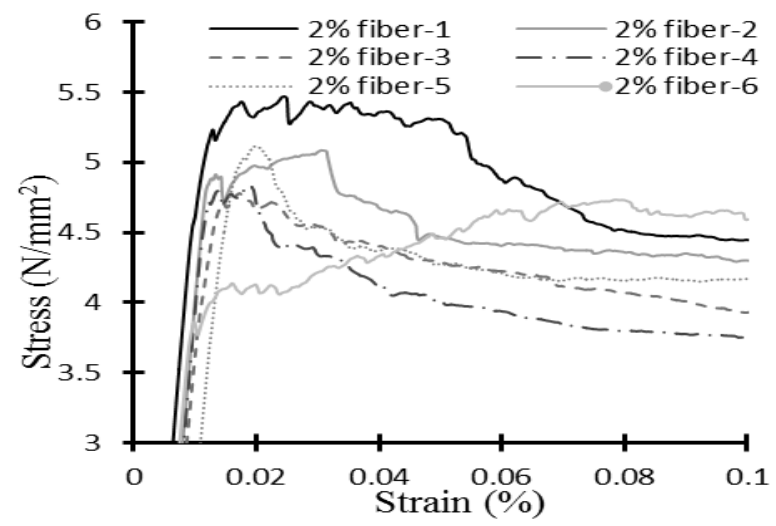

$(3 \mathrm{c})$

Fig.3 The Effects of Fiber Volume on Compressive Stress-strain Curves (2a. 1\% Fiber Volume; 2 b. $1.5 \%$ Fiber Volume; 2c. 2\% Fiber Volume)

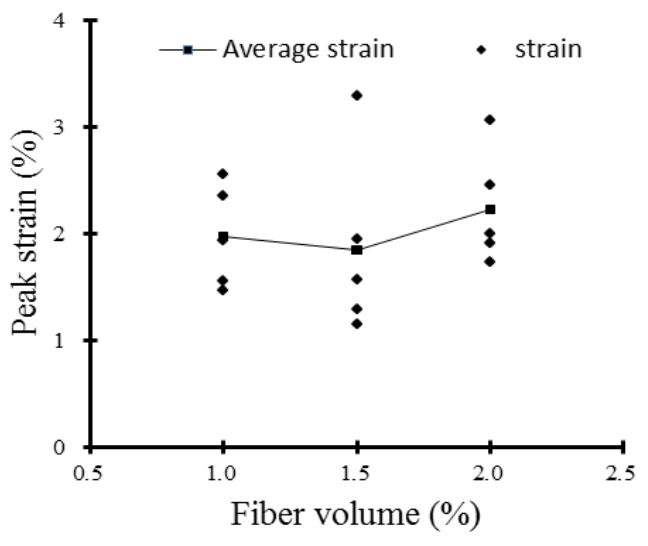

(4a)

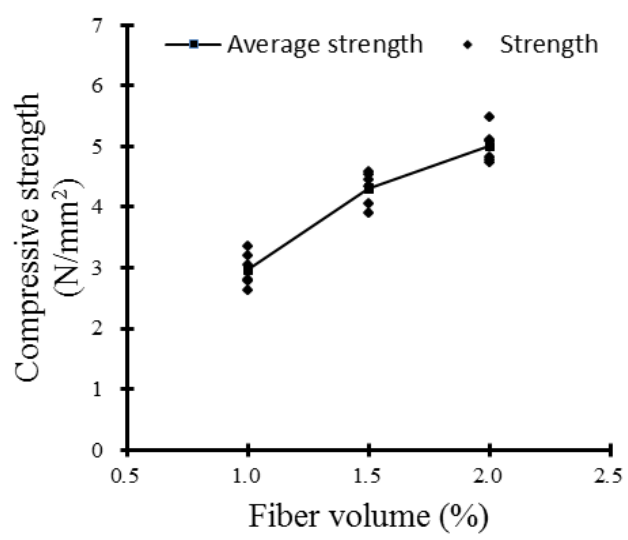

(4b)

Fig.4 The Effects of Fiber Volume on Ultimate Strength and Compressive Strain Capacity (4a. On Ultimate Strength; 4b. On Ultimate Strain)

\section{Summary}

This study mainly presented the mechanical property tests for three kinds of ULFR-ECC with different fiber content and introduced the strain-stress curves of its tension and compression based on the result of tests. According to the analysis of related data, certain conclusions could be made as follows: 
(1) The light weight ULFR-ECC has been made successfully by using PVA fiber and K20, and the dry density of it is about $566 \mathrm{~kg} / \mathrm{m}^{3}$. Multi-cracks were founded during the tensile strength test of the produced ULFR-ECC, which proved an excellent ductility of the material. Except the ULFR-ECC with a fiber content of $1 \%$ which was softened in the later stage of tensile test, the other two kinds of ULFR-ECC with fiber content of $1.5 \%$ and $2 \%$ both showed the feature of strain hardening.

(2) ULFR-ECC with the fiber content of $1 \%, 1.5 \%$ and $2 \%$ showed their peak tensile strength of $2.17 \%, 2.73 \%$ and $2.81 \%$ respectively. The rise of fiber content is helpful to increase the tensile strength, the fracture strength, the tensile elasticity modulus, the crack-width control ability and the resilience of ULFR-ECC.

(3) During the process of compressive test, ULFR-ECC with deformation could still bear a comparatively high load even though the force might have exceeded the peak loading. Besides, no rapid brittle fracture was found under this circumstance. The results above have proved that ULFR-ECC has great superiority in compressive strength and resilience. In addition, the rise of fiber content can make great help to increase the compressive strength of ULFR-ECC.

\section{Acknowledgement}

The authors wish to express their gratitude to the National Natural Science Foundation of China for the financial support provided under project.

\section{References}

[1] G.J. Wang, J.Y. Yang, Influences of binder on fire protection and anticorrosion properties of intumescent fire resistive coating for steel structure, J. Surface and Coatings Technology 204 (2010) 1186-1192.

[2] S. Ullah, F. Ahmad, A.M. Shariff, M.A. Bustam, Synergistic effects of kaolin clay on intumescent fire retardant coating composition for fire protection of structural steel substrate, J. Polymer Degradation and Stability 110(2014) 91-103.

[3] S.Y Liang, N. M Neisius, S. Gaan, Recent developments in flame retardant polymeric coatings, J. Progress in Organic Coatings 76(2013) 1642-1665.

[4] S.H. Said, H.A. Razak, I. Othman, Flexural behavior of engineered cementitious composite (ECC) slabs with polyvinyl alcohol fibers, J. Construction and Building Materials 75(2015) 176-188.

[5] Z.F Pan, C. Wu, J.Z Liu, W. Wang, J.W Liu, Study on mechanical properties of cost-effective polyvinyl alcohol engineered cementitious composites (PVA-ECC), J. Construction and Building Materials, 78(2015) 397-404.

[6] Q. Zhang, V.C. Li, Development of durable spray-applied fire-resistive Engineered Cementitious Composites (SFR-ECC), J. Cement and Concrete Composites, 60(2015) 10-16.

[7] X.Y Huang, R. Ranade, Q. Zhang, W. Ni, V.C. Li, Mechanical and thermal properties of green lightweight engineered cementitious composites, J. Construction and Building Materials, 48(2013) 954-960.

[8] Q. Zhang, V.C. Li, Adhesive bonding of fire-resistive engineered cementitious composites (ECC) to steel, J. Construction and Building Materials 64(2014) 431-439. 
[9] Q. Zhang, R. Ranade, V.C. Li, Feasibility study on fire-resistive engineered cementitious composites, J. ACI Materials Journal 111(2014) 651-660.

[10] JSCE, Recommendations for design and construction of high performance fiber reinforced cement composites with multiple fine cracks, Japan Society of Civil Engineers, Tokyo (2008) pp. $1-16$.

[11] ASTM E605/E605M - 93, "Standard Test Methods for Thickness and Density of Sprayed Fire-Resistive Material (SFRM) Applied to Structural Members1.” ASTM International, West Conshohocken, PA, 2007, pp 1-6.

[12] ASTM C109/C109M-16a, "Standard Test Method for Compressive Strength of Hydraulic

Cement Mortars (Using 2-in. or [50-mm] Cube Specimens)," ASTM International, West Conshohocken, PA, 2002, pp 1-10.

[13] K. Tosun-Felekoğlu, B. Felekoğlu, R. Ranade, B.Y. Lee, V.C. Li, The role of flaw size and fiber distribution on tensile ductility of PVA-ECC, J. Composites Part B: Engineering, 56(2014), 536-545.

[14] Y.Li, Z.J.Liu, X.W.Liang, Tensile performance of high performance PVA fiber reinforced cementitious composites under uniaxial tension, J. Engineering Mechanics, 30(2013), 322-330.

[15] V.C. Li, Y.J Wang, S. Backer, A micromechanical model of tension-softening and bridging toughening of short random fiber reinforced brittle matrix composites, J. Journal of the Mechanics and Physics of Solids, 39(1991), 607-625. 